\title{
Promotion of Vocational Education by Transferring Notions and All-Round Cultivation
}

\author{
Peng Tong \\ Department of Power Engineering \\ Baoding Technical College of Electric Power \\ Baoding, Country \\ tptong@163.com
}

\author{
Mingxing Zhao and Ke Ma \\ Department of Admin \\ Baoding Technical College of Electric Power \\ Baoding, Country
}

\begin{abstract}
The continuous development of economy in our country needs a large number of high-quality practical talents. Higher vocational colleges must keep up the pace, implement the scientific concept of development, people-oriented, combined with the actual, and explore the profound connotation of students' comprehensive quality. Therefore, as determined by the essential task of vocational colleges, the moral-education-first principle rather than teaching-oriented principle needs to be adhered to with the attempt to push the work forward, which can be achieved by developing various mechanisms to ensure that comprehensive qualities of students can be promoted and moral education can be conducted by everyone and anywhere in any cases.
\end{abstract}

Keywords-notion transformation; moral education; development; higher vocational colleges

\section{INTRODUCTION}

Currently the transfer from teaching-oriented principle to the education-oriented principle has gradually occurred in higher vocational colleges, which is guided by the notion proposed in the Report of the Seventeenth Party Congressthe party's education policy need to be implemented fully [1], and the moral-education-first principle need to be adopted to achieve the all-round development of the students. Thus, further progress of the vocational education can only be realized theoretically and practically by constructing educational pattern carefully, being pragmatic and practical, and pursuing excellence with the education-oriented principle as focus, which are regarded as the essential tasks and inevitable options of vocational education.

Education refers to cultivate people who can commit themselves to the society, which determines that colleges should educate people by the means of teaching, because it is more significant for the students to learn to behave like a man than to acquire certain skills. This notion has been proved and advanced by various experts home and abroad. Zhang Zai, the great philosopher in Song Dynasty, maintains learning to be a man, while Rousseau, the French educator, argues that a man grows by education. Therefore, only by concentrating on the education, the work of various departments can be coordinated to fulfill the purpose of educating people by the means of teaching, management, service and environment to the fullest extent.

\section{THE PRESENT CONDITION OF HIGHER VOCATIONAL EDUCATION}

\section{A. Comprehensive Quality Actuality of Higher Vocational Students}

Moral qualities: Despite of the strong request to make progress politically, the students have weak foundation knowledge of political theory and poor ability of distinguishing the right from the wrong. Contrasted to the majority who hold the positive, practical and healthy value judgment criteria, some students become utilitarian with extreme individualism, lacking collectivism value and devoting spirit. Furthermore, many of them don't know how to take care of others and how to be grateful to parents or other elders. Their self-discipline also needs to be improved.

Cultural qualities: Despite of the increased time stress and strong desire to be successful, most students have weak foundation and hard-working spirit.

Specialty skills: Majority of them long for a certain skill, but usually lack perseverance because they cannot live with the boring training.

Psychological quality: Many students bear low acceptance to vocational education, lacking confidence and holding an attitude of exclusion and resistance. As a result, they are indifferent to collective affaires, go their own ways and lack self-discipline and life goals.

\section{B. Problems of Vocational Education}

On major problem in many higher vocational colleges is that the education-oriented target is usually weakened and broken up into a specific task instead of a systematic approach. That is, moral education is separated from the teaching process and acts as an isolated task completed by certain group of people. In many cases, moral education is solely associated with the teachers of ideology politics lessons, cadres or assistant for political and ideological work. Besides, most teachers don't realize the importance of moral education and only instruct certain theories or skills in class. As a result, the oral education is totally cut from the teaching process of various subjects and cannot be integrated into other areas, such as academic education, physical education or administrative service, which makes it difficult to form a team composed by 
both full-time and part-time people from different levels and makes the "concerted effort" become a kind of formality.

\section{Education is the Basic Goal of Higher Vocational Colleges}

The solution of this problem depends on raising awareness, effective measures and efficient implementation. In the first place, the higher vocational colleges need to raise the education-oriented awareness, which serves as the base of talent cultivation. Just as what is proposed in the Outline of China's the Eleventh Five-year Plan, the essential task of education is to cultivate the students morally, colleges, as the important bases for talent cultivation, should produce wellrounded builders and successors for the socialist cause with lofty ideals, integrity, knowledge and discipline[2, 3]. All the functions, tasks and work in higher vocational colleges need to surround and serve this target.

\section{TRY TO ESTABLISH A MECHANISM FOR ALL-ROUND EDUCATION}

The mechanism of involving everyone, from the principal to faculty, in the course of moral education needs to be established to make sure that the new notion (moral education can be conducted by anyone and anywhere in any cases) is clarified to everyone, which is one of the most urgent tasks the higher vocational colleges face up to. The detailed procedures and suggestions are as follows.

\section{A. Forming Educational Concepts Update Mechanism}

There are several ways to renew the notions of educators. Firstly, the correct moral-education-first notion can be formed by deepening theoretical studies of higher education, such as analyzing relative works or holding seminar regularly. Such studies are vital for the entire faculty, especially the young who lack practical experience. The topics need to cover the principles of education, philosophy and psychology, which also need to be connected with the teaching, researching, social servicing and administrative practice to guarantee the establishment of correct moral-education-first notion. This approach need to be fixed down as a norm and system to take regularly, which enables our faculty to be ready and good at delivering such notion into the practice to guide and inspire the students to refine their sentiments and improve morally.

Secondly, the notion-renewal forum can be opened online to let the teachers and administrators to share their ideas after theoretical studies or summarize the experience or achievements in practice. Regular lectures, report meeting or even debate can be hold, and college newspapers and magazines can be employed as the channel to advocate new theories, notions or approaches of moral education to broaden the horizon and popularize the experience [4].

\section{B. The Participation Mechanism}

The fulfillment of this target requires that everyone involves in all the stages of education from various perspective, which need to be achieved through 3 aspects. First, the target of talent cultivation needs to be regarded as the aim of all the work in higher vocational colleges despite of the fact that the form and content of work in different department vary from each other. Second, objective assessment mechanism can be introduced by specifying the specific objectives, contents and tasks of each department to make sure that the objectives can be adhered to in the long run. Third, the responsibility system needs to be established to clarify the duties shouldered by the whole team and individuals based on the jobs accordingly. Thus, when problems arise, the prompt and efficient solutions can be figured out. Fourth, the full-time teachers need to share the work related to students by acting as class teacher, supervisor, or assistant for political and ideological work to extend the channel of communication between teachers and students.

\section{The Incentive Mechanism}

Presently, attention has been given more to the professional development and administrative affairs than to the achievement faculty have made in moral education. Besides, the targets are either too abstract to be applied or too low-proportioned to be paid attention to, which result in the failure of motivating the faculty to fulfill the target. Therefore, the assessment proportion of achievement in moral education needs to be increased in the first place to make it become the major aspect, because we cannot equate talent cultivation with teaching workload. Instead, we need to encourage the construction of quality courses and inspire the teachers to make teaching reform. Second, the criteria and targets need to be more specific, practical and feasible to assess the faculty's jobrelated achievement. Third, the assessment result of achievement in moral education needs to be connected with the promotion, rewards or punishment to make sure that the one who is unwilling to or cannot fulfill the moral education tasks will not have the opportunity for promotion.

\section{THERE ARE 2 MAJOR ASPECTS BEING PAID ATTENTION TO IN MORAL EDUCATION}

\section{A. Educating Team Building}

The moral education team needs to be formed with the assistants for political and ideological work as the backbone, whose duties are to set up rules and regulations and to conduct the assessment. The full-time teachers need to shoulder the responsibilities of helping students foster the morally sound values and outlook, obtain appropriate learning strategies, access the development in relative professions and solve the problems. The students cadres are another force to facilitate the management, whose radiation effect can be boosted by constant and gradual practice and guidance from the teachers.

\section{B. Improving the Ability of Higher Vocational Teachers Education}

The moral education ability of the faculty needs to be enhanced by perfecting the assessment mechanism and training system. In the teaching practice, the assessment usually focuses more on the teaching levels than moral education. In fact, teacher's ability in dealing with emergencies, organizing activities, communicating with troubled youngsters, and integrating moral education in the teaching content are of great significance to the smooth implementation of teaching plan [5]. Therefore, praise needs to be given to the capable teachers, 
while guidance and encouragement need to be given to the novice teachers. Moreover, relative policies and measures should be made with the attempt to carry out the training concerning educational theories and let the capable teachers pass on their experience to novice ones by solving practical problems.

\section{DISCUSSION}

\section{A. Knowledge Education and Cultural Education}

From the perspective of educational interpretation, knowledge and culture are usually treated as one subject. In fact, they bear great differences. Knowledge, such as scientific or geographic knowledge, refers to the experience accumulated by human being in the daily social practice. On the other hand, culture is richer in content, referring to wisdom, literacy and spirit based on and distillated from knowledge. Culture without knowledge is like a tree without roots; while knowledge without culture is like a boat without rudder [6]. The educational institutions' perception of these differences reflects various attitudes towards and levels of education.

\section{B. The Library Educational Function}

As the treasure of human knowledge and culture, library is an indispensable sphere of education. The full realization of its cultural function can achieve the purposes of arming students with scientific theories, guarding them with correct opinions, remolding them with lofty ideals and inspiring them with excellent works [7]. Therefore, it is particularly significant for the vocational colleges to nourish students' spiritual world with library.

\section{The Educational Function of Campus Culture}

Splendid campus culture has the functions of orientation, discipline, integration, inspiration and radiation. From the aspects of spiritual culture, material culture and system culture, progressive spirit, scientific and democratic value system and correct public opinion orientation can be fostered by developing beautiful campus environment, colorful cultural life, elegant artistic taste, dense academic atmosphere and scientific humanistic spirit [8]. Therefore, the psychological balance of students and staff can be achieved, campus activities and personality charm can complement each other and general quality education can be realized.

\section{CONCLUSIONS}

In conclusion, vocal colleges should adhere to the moraleducation-first principle to serve for the job-oriented education. And people at all levels should raise the awareness of the significance of moral education and do their utmost to implement it in teaching, managing and servicing process. Thus, the construction of all-round education can produce the qualified people with lofty aspiration, excellent skills and practical style, who can commit themselves to the social and economic development.

\section{ACKNOWLEDGMENT}

This study was supported by grants from the project of Association of Higher Education of Hebei Province (No. GJXH2015-321).

\section{REFERENCES}

[1] Jintao $\mathrm{Hu}$, The report of the 17th national congress of the Chinese communist party. People's Publishing House, 2007: 37. (In Chinese)

[2] Ministry of Education, The 11th five-year plan outline of National education career development. The 11th five-year plan outline of National education career development forwarded to the ministry of education by the state council. (In Chinese)

[3] Ministry of Education,. The opinion about strengthening the team construction of high school counselors and teachers. Teach social administration, 2005. 2. (In Chinese)

[4] Meiyi Gao, How to do a good job of higher vocational freshmen class teacher. Science \& Technology information, 2009. (2): p. 331-332. (In Chinese)

[5] Weidong Wang, Xuliang Liu, Production education is the new idea of improving higher vocational moral education system. Education and Vocation, 2006. 517(21): 128-129. (In Chinese)

[6] Yuntao Chen, The construction and thinking of higher vocational colleges culture education system. Higher Education Exploration, 2009. (4): p. 113-115. (In Chinese)

[7] Wanyang Liu, The spirit self-restrainted by cultural-Higher vocational college library education function. Vocational education, 2008. (1): p. 61. (In Chinese)

[8] Jibi Tang, Discussion on higher vocational education students' comprehensive quality. Science \& Technology information, 2008. (9): p. 156-157. (In Chinese) 